\title{
How Informational Integration Can Improve The Relationship Between Buyer And Supplier Of Logistical Services: Empirical Evidence From Vietnam
}

\author{
Huu Tuyen Duong, Ph.D., University of Transport \& Communications, Vietnam
} Gilles Paché, Ph.D., Aix-Marseille University, CRET-LOG, France

\begin{abstract}
Having initiated economic liberalization in 1986, Vietnam is a particularly interesting emerging economy to study. The logistics industry in the country is developing strongly because manufacturers are willing to outsource their logistical activities to specialized businesses called logistics service providers (LSPS). To be sustainable partners of manufacturers, LSPs must adopt an informational integration policy that improves the functioning of their customers' supply chains. To find out whether Vietnamese manufacturers value information integration, a questionnaire survey was administered to 139 food industry managers. The main research finding is that informational integration between manufacturer and LSP strongly impacts the manager's perception of its own logistics performance. This result has major implications for foreign LSPs that want to carve out a significant place on the Vietnamese market.
\end{abstract}

Keywords: Food Industry; Informational Integration; Logistics Service Provider (LSP); Supply Chain; Vietnam

\section{INTRODUCTION}

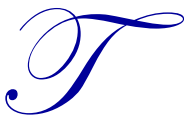

he many strategic and organizational facets of the logistics industry have drawn scholarly attention, which had long been limited to purely technical dimensions linked to transport and storing operations. This evolution is particularly positive because logistics service providers (LSPs) had indeed been seeking to better position their offer; a LSP is a company that provides extended logistical services to shippers, including transport, handle shipping, inventory, warehousing, packaging and postponement activities. As this type of questioning has become central to analysis, and deservedly so, it raises the importance of examining relations between LSPs and shippers that are most conducive to optimizing the offer of logistics services. Thus, when an LSP develops high value services, it will undoubtedly consider, with its customer, whether the supply chain can be integrated significantly to improve interface management and resulting performance. In fact, the abundant studies of the link between supply chain integration and performance underline that supply chain integration is a major theme (Kim, 2013).

Several academic studies have examined the impact of supply chain integration on firm performance. Some have focused on the global impact of integration on performance (Dröge et al., 2004), whereas others explore the impact on performance of internal (Stank et al., 2001) or external integration (Gimenez and Ventura, 2005). The impact of integration on internal firm performance (Dröge et al., 2004), notably the production process (Swink et al., 2007), or new product development (Jayaram and Tan, 2010), has also been investigated. In the relationship between LSPs and shippers, shippers rely on LSPs to deliver their products on the market, and even to design their distribution system. The overall goal is to ensure maximal satisfaction of the end customer. The LSP thus contributes the logistics resources that the manufacturer lacks, under the right cost and service conditions. Hertz and Alfredsson (2003) conclude that integration between the two partners suffices to generate a competitive advantage for each partner. The value of studying the dyadic relationship between the shipper and the LSP as part of supply chain functioning thus seems evident. 
To our knowledge, few empirical studies have examined integrated processes between shippers and their LSPs. Halldórsson and Skjøtt-Larsen (2004) propose four levels of supply chain integration, whereas Mortensen and Lemoine (2008) analyze the degree of supply chain integration through eight management processes. More recently, Jayaram and Tan (2010) examined the impact of informational integration factors of the LSP on perceived performance by the shipper. Although this research has made undeniable contributions, there is still much to investigate, notably regarding informational integration of the supply chain between the manufacturer and its LSP. We define integration as the degree to which a manufacturer uses a collaboration strategy with its LSP to improve logistics process management. The manufacturer's objective is to derive effective management of product performance flows from this close and sustainable collaboration, which would be much more efficient than had the two parties simply engaged in the purchase and sale of logistics services under spot contracts.

Vietnam has been retained as a field of investigation because in 1986 the country initiated a reform called Doi Moi [renovation], which has changed its economic model dramatically. The move from a planned economy to a market economy should attract numerous foreign direct investments (Meyer et al., 2006; Lam, 2011). Further, to our knowledge no scholarly research has been conducted on the dyadic integration of the supply chain in this country. This gap raises a problem given that the shift to a market economy exacerbates competitive pressure and obliges businesses to differentiate themselves through a more aggressive pricing and/or service policy. The cultural context is characterized by a mix of traditional and modernity; logistics is still confined to short-term contractual exchanges (Dao, 2011) within a gradual evolution toward new dynamics. A powerful logistics industry is thus taking shape. As one example, Weixin, founded in 1994, is the first private company in Vietnam operating as an international freight forwarder. Today the company offers enlarged logistics services on the Vietnamese market, from transportation of general cargo, over-weight and over-height cargo, to packing, warehousing and delivery of all kinds of products using its own information systems.

The Weixin case is not an isolated one. Rhenus Logistics, Nippon Express, DB Schenker or the famous DHL, the world's leading cross-border express services provider, all think that Vietnam offers major growth opportunities for the coming years, and that they can play an indispensable role in allowing manufacturers to make their supply chains more reliable, particularly in terms of food security and service quality. Without totally reliable supply chains, capable of real risk mitigation, manufacturers risk losing market share to better organized competitors in a new marketing context: customer satisfaction is today among the most important driver of corporate performance for privatized firm in Vietnam (Vo et al., 2013). Exploring the relationship between manufacturers and LSPs in this particular context is therefore relevant. The objective of this paper is to analyze the extent that informational integration of a supply chain between a supplier and a logistics services customer leads to perception of strongly increased performance by the manufacturer. If this causality is affirmed, this would mean that LSPs that have put in place efficient information systems have a sustainable competitive advantage.

\section{THEORETICAL BACKGROUND}

Alfalla-Luque et al. (2012) identify three essential dimensions to understand issues in supply chain integration. First, supply chain integration rests on a will to improve coordination, shared by all stakeholders. Supply chain integration also implies the implementation of collective value creation process. Lastly, concrete supply chain integration requires sharing of monitoring data among supply chain members, along with physical and human resources. The important question is whether this integration positively affects the logistics performance of the buyer of logistics services, compared with the performance resulting from its own account logistics.

\section{Logistics Performance}

The concept of logistics performance emerged form reflection on distribution cost analysis initiated in the USA in the mid-1950s. What do "performance" and "logistics performance" really mean? Performance has at least three meanings or connotations: a success, the result of an action, without an associated value judgment (the value of the performance), or an action, in the conventional sense. By nature, performance is multidimensional (Chow et al., 1994), and its definition is a real challenge for researchers in all areas of management because organizations often have multiple objectives, and objectives habitually come into conflict. Some objectives may be approached in terms of profits or shareholder compensation, whereas others may pertain more to customer service and sales maximization. 
Lastly, we can construe performance in a logic of efficiency and effectiveness, namely relative to the output of the organization. Neely et al. (1995) define performance as efficiency and effectiveness of actions in a given business context. Effectiveness corresponds to meeting customer's requirements, whereas efficiency refers to the resources the organization uses to attain targeted levels of customer satisfaction. Consequently, one can say that performance measurement systems are sets of parameters that serve to quantify efficiency and effectiveness. This reasoning evidently applies to supply chains as networks of organizations, working together to attain a common objective: satisfaction of the end customer. Generally, logistics performance includes hard measures, such as logistic service, costs and investments; and soft measures such as perception of satisfaction and customer loyalty (Beamon, 1999).

Conceptually, logistics performance can also be seen as a subset of the broader concept of organizational output. This concept has attracted the attention of the growing number of researchers. Chow et al. (1994) maintain that performance refers to effectiveness, efficiency, quality, productivity, innovation and profitability. In a supply chain context, performance includes indicators like lead times, flexibility and delivery times, all generated by continuous action among supply chain members (Forslund, 2012). Wilding and Juriado (2004) assert that the acquisition, analysis and presentation of performance data is a success factor for LSPs and their customers. Liu et al. (2010) argue that customers perceive LSPs' ability to attain high performance as particularly important for their competitiveness. Wilding and Juriado (2004) find that many shippers consulted use a highly formalized performance measure in their relationships with their LSPs.

\section{Informational Integration}

In the logistics context, the information system meets three main features: (1) to coordinate the product flow throughout the supply chain; (2) to monitor the logistical processes ; (3) to control the processes at operational level, particularly in transport and storage. Prajogo and Olhager (2012) assert that informational integration entails the sharing of key information within the supply chain, activated by information technologies whose main quality is to be able to dissociate execution decisions from control decisions. When firms participate in integrating the supply chain, they share management data (Lee, 2000; Saeed et al., 2005; Kim and Lee 2010; Leuschner et al., 2013). This sharing is one of the key elements of the informational integration process; it allows organizations to improve reliability and speed of execution of operations (Panayides and Song, 2008). Informational integration thus refers to coordination of information transfer, collaboration in business-to-business communication, and technological support provided to supply chain members (Leuschner et al., 2013).

The exchange of information rest on firms' capacity to effectively and efficiently share their knowledge with partners (Wu et al., 2006). This knowledge fosters short-term coordination of flows along with long-term improvement of supply chain functioning (Mackelprang et al., 2014). For the partners to be able to optimally use the information shared, it must be exchanged instantly as needed. The source of information must therefore be credible and the format adequate (Wu et al., 2006). Effective information exchange has been identified as one of the most fundamental capacities in the supply chain integration process (Shore and Venkatachalam, 2003). For supply chain members, sharing monitoring data provides essential advantages (Hsu et al., 2008): information is distributed throughout the supply chain, senders and receivers of information become closer, and partners can respond to the product flow in a timely manner.

Informational integration thus refers to the extent that crucial information is available to all supply chain members. Data can be shared at two levels: (1) tactical, e.g. information on purchases, operation planning; and (2) strategic, e.g., information on the firm's long-term objectives (Hsu et al., 2008). Kulp et al. (2004) specify two important dimensions: information exchanges and collaborative planning. Information exchanges include sharing of data on final demand and on inventory status whereas collaborative planning refers to synchronization of activities among supply chain members. Specifically, the partners collaborate by transferring responsibility for the order among supply chain members, replenishing and liquidating inventories, using jointly developed logistics mechanisms, and coordinating design, development and introduction of new products.

Closs and Savitskie (2003) contend that it is difficult to envision informational integration among supply chain members without a sufficient capacity to integrate technologies between the LSP and its shipper, notably software that facilitates the execution of logistics activities (order management, inventory, storage, transport, etc.). Prajogo 
and Olhager (2012) note that information technologies allow a business to increase the volume and complexity of the data that must be communicated to its partners. Advanced technological tools can provide real-time information, including on inventory levels, delivery status and production planning. These tools also simplify alignment of forecasts and planning of operations between partners, thus improving business-to-business coordination (Prajogo and Olhager, 2012). To summarize, informational integration between the shipper and its LSP rest on a strategic will to share data to improve logistics interface management and on a sufficient technological capacity in the operational implementation of interfacing.

\section{Link Between Informational Integration and Perceived Logistics Performance}

The advantages of information exchange and of supply chain integration have been frequently reported in the literature (Sezen, 2008). Many studies have shown that sharing of data among supply chain members improves competitiveness and logistics performance (Berry and Naim, 1996; Closs and Bowersox, 1997; Sahin and Robinson $\mathrm{Jr}, 2005)$. Increasing integration and data sharing has become necessary to improve supply chain effectiveness. Firms' cooperative behaviors indeed offer quick access to information required, greater sensitivity to customers' needs, and a quicker response time than the competition (Sezen, 2008). Previous works have demonstrated a positive relationship between the level of informational integration of the supply chain and performance (Zailani and Rajagopal, 2005; Kim, 2006; Mackelprang et al., 2014).

Supply chains grounded in shared information create value for the actors by decreasing costs and increasing market share (Lee, 2000). The result is successful integration that lets firms reduce their inventory, cycle times, cash flows, and purchasing costs of materials, while increasing labor efficiency and improving responsiveness to customers (Lummus and Vokurka, 1999). Similarly, the ability to quickly obtain information on demand can lower storage costs (Lee, 2000). When the flow of information in the supply chain supersedes physical flows of materials and merchandise, inventory reduction and efficient use of resources is possible (Graham and Hardaker, 2000). Strader and Shaw (1999) demonstrate that sharing of data on supply and demand in the supply chain can reduce storage costs and shorten order cycle time.

Researchers have also found that data sharing increases supply chains' ability to react to abrupt changes in demand in a highly turbulent environment (Lee, 2000; Mackelprang et al., 2014). According to Zhao et al. (2002), information sharing directly influences supply chain performance in terms of cost and service level. Similarly, Lin $e t$ al. (2002) emphasize that a high level of sharing of monitoring data is associated with total cost reduction and shortening of the cycle. However, although sharing of monitoring data is crucial, its impact on supply chain performance depends on what this information contains ("monologic" vs. "dialogic" data), and how and with whom it is shared (Holmberg, 2000).

The faster and the more reliably information circulates within the supply chain, the less time it will take to make adjustments due to unforeseen circumstances, thus implying more flexibility in operations management and deliveries. However, high levels of coordination and integration between organizations may reduce their capacity and willingness to make rapid changes in business relationships (White et al., 2005). Paixão and Marlow (2003) and Panayides and Song (2008) argue that development of information and data sharing systems may have a strong influence on the degree of integration, in that it allows firms to avoid duplicating documents, improve information processing by all supply chain actors and reduce logistics costs. Based on this research, we conclude that there is a positive relationship between informational integration and logistics performance perceived by the manufacturer. We consequently hypothesize that: Logistics performance is perceived by the manufacturer as improved if the manufacturer and its LSP developed an informational integration policy.

\section{MEASUREMENT SCALES}

This paper examines the relationship between perception of logistics performance by the manufacturer and the informational integration capacities of the supply chain between the manufacturer and its LSP. We are particularly interested in studying the interface between shipper and LSP from a dyadic perspective, in order to assess the integration prevailing in the relationship between a manufacturer and its main LSP, from the shipper's viewpoint. The operationalization of variables rests on previously developed measurement scales. However, we have adapted 
the scale to our study by consulting academic and professional experts, and conducted a pre-test in the field. Most of the variables used are adapted to the Vietnamese context; the indicators forming the variables presented result from this adaptation.

\section{Logistics Performance Perceived by the Manufacturer}

Measuring logistics performance is a recurring problem in the academic research. It is true that in a context of hyper-competition, the competitive advantage linked to control of delivery times or reduction of logistics costs can be vital. As noted, logistics performance is generally attracting much attention among scholars and practitioners because it largely reflects overall firm performance. For instance, Green Jr. et al. (2008) find that logistics performance has a significant impact on a firm's marketing and financial performance. Chow et al. (1994) argue that defining and measuring logistics performance are very difficult for businesses. Indeed, this topic is proliferating in the literature.

According to Forslund (2012), logistics performance is generally linked to delivery service, logistics costs and capital costs. Delivery service can be measured by delivery times, logistics costs are linked to transport and storage, whereas capital cost concerns inventories of materials, components or finished products. Rodrigues et al. (2004) use six items: logistics costs, delivery time, delivery reliability, order execution capacity, inventory rotation and customer satisfaction. Green Jr. et al. (2008) adapt the measurement criteria of logistics performance developed by Bowersox et al. (2000), which include customer satisfaction, delivery speed, delivery reliability and flexibility (quick adaptation to customers' changing needs). More recently, Hsiao et al. (2010) used a six-item scale to measure logistics performance, developed by Stank et al. (2001) and Rodrigues et al. (2004).

Among the indicators identified in the literature on logistics performance, those proposed by Stank et al. (2001) appear particularly intriguing because they cover the various assets of this performance exhaustively. Consequently, owing to their robustness, we retain the measurement scales of Stank et al. (2001). They are presented in table 1. Respondents were asked the following general question: How do you perceive the positive impact of the use of a LSP on your logistics performance for the following criteria? The scale ranges from "not important at all" to "very important." Note that we are studying the manufacturer's perception of logistics performance, rather than relying on internal data (indicators) related to logistics performance observed. This information is impossible to obtain in an emerging economy like Vietnam, strongly marked by extensive concealment of financial data and corruption. Table 1 summarizes what the manufacturer perceives as important to improve its logistics performance in concert with its LSP.

Table 1. Indicators of the variable "logistics performance perceived by the manufacturer" (LP)

\begin{tabular}{llc} 
Code & \multicolumn{1}{c}{ Items } & Type of scale \\
\hline LP_01 & Prior notice of shipping & 5-point Likert \\
LP_02 & Customer satisfaction & Id. \\
LP_03 & Compliance with delivery times & Id. \\
LP_04 & Delivery speed & Id. \\
LP_05 & Flexibility of delivery time & Id. \\
LP_06 & Inventory rotation & Id. \\
LP_07 & Information systems support & Id. \\
LP_08 & Logistics costs reduction & Id. \\
LP_09 & Order fulfilment capacity & Id. \\
LP_10 & Order flexibility & Id. \\
LP_11 & Responsiveness to key customers & Id. \\
\hline
\end{tabular}

Source: Adapted from Stank et al. (2001).

\section{Informational Integration Between the Manufacturer and Its LSP}

Integration of information systems refers to the extent that a firm develops systems and information technologies to facilitate supply chain management (Rodrigues et al., 2004). More generally, supply chain information systems are known to actively contribute to the success of a lean supply chain strategy by improving firm performance (Qrunfleh and Tarafdar, 2014). Integration of information systems, or informational integration, has been evaluated in different 
ways in the literature, with reference to different items. For instance, Hsu et al. (2008) cite Shore and Venkatachalam (2003), Iyer et al. (2004), Auramo et al. (2005), Savitskie (2007) and Kärkkäinen et al. (2007), who portray informational integration as a one-dimensional construct made up of six items. Kulp et al. (2004) consider that informational integration between firms can be measured by three items concerning the intensity and range of data sharing.

Prajogo and Olhager (2012), who revisit the work of Narasimhan and Kim (2002), Frohlich and Westbrook (2002), Gunasekaran and Ngai (2003), Sanders and Premus (2005), and Devaraj et al. (2007), assert that informational integration refers to two distinct realities: (1) a technological perspective (interconnection and interoperability of information systems); and (2) a social perspective (data sharing based on trust between partners). Yu et al. (2001), Narasimhan and Nair (2005), Carr et al. (2008), Li and Zhang (2008) and Sezen (2008) also underline the importance of sharing monitoring data between businesses to enhance the functioning of supply chains. The consensus in the literature appears strong enough to suggest an undeniable significant and positive impact of informational integration on logistics performance.

Several researchers have raised the question of indicators to retain when evaluating the degree of informational integration (Maloni and Carter, 2006; Skjoett-Larsen et al., 2006; Mortensen and Lemoine, 2008; Jayaram and Tan, 2010). Among the indicators identified in the literature, those developed by Kulp et al. (2004), Hsu et al. (2008) and Jayaram and Tan (2010) seem particularly robust. They have proven to be relevant, and the authors that used them confirm their eminent operability in terms respondent comprehension. We present them in table 2. Respondents were asked the following general question: How do you agree or disagree with the following statements that describe informational integration between your firm and your main LSP? The scale ranges from "disagree completely" to "agree completely." The main LSP is that for which the shipper purchased the most logistics services, which eliminates backup LSPs with whom transactions may be only ad hoc (a few days in duration).

Table 2. Indicators of the variable "informational integration" (II)

\begin{tabular}{llcl}
\hline Code & \multicolumn{1}{c}{ Items } & $\begin{array}{c}\text { Type of } \\
\text { scale }\end{array}$ & Authors \\
\hline II_01 & Use of informal data sharing modes & 5-point & Hsu et al. (2008) \\
Likert & Jayaram and Tan (2010) \\
Id. & Hsu et al. (2008) \\
II_02 & Use of formal data sharing modes & Jayaram and Tan (2010) \\
& & Id. & Jayaram and Tan (2010) \\
II_03 & Improving the integration of activities across your supply chain & Id. & Jayaram and Tan (2010) \\
II_04 & Communicating your firm's future strategic needs to your suppliers and carriers & Id. & Jayaram and Tan (2010) \\
II_05 & Creating a compatible information system with suppliers, carriers, and customers & Id. & Kulp et al. (2004) \\
II_06 & Sharing of customer data & Id. & Kulp et al. (2004) \\
II_07 & Sharing of data on demand for new services/products & \\
\hline
\end{tabular}

\section{QUESTIONNAIRE AND SAMPLE STRUCTURE}

Vietnam is a collectivist emerging economy that is drawing growing attention because the country has embarked on the policy of economic liberalization that promotes its openness to the world (Vo et al., 2013). Despite recent efforts in this area, logistics infrastructures still need improvement to allow businesses to supply markets effectively. The many shortcomings in Vietnamese logistics organization are not solely attributable to infrastructures; they are also linked to the flawed regulation policy and to corruption (Banomyong et al., 2015), although progress has been made. For our research, we decided to administer a questionnaire survey owing to the lack of quality secondary data in the logistics field. We produced a 23-question questionnaire structured as follows: (1) questions related to general information on the business (5 questions); (2) questions related to the variable "informational integration between manufacturer and LSP" (7 questions); and (3) questions related to perceived logistics performance (11 questions). The survey was conducted directly in Vietnam, in February and March 2014.

We chose Vietnamese food manufacturers that deal with LSPs for logistics outsourcing. According to the General Statistics Office of Vietnam, of the 7,466 food sector manufacturers operating in Vietnam in 2012, 3,440 businesses (46.1\%) are located in the south of the country, around the economic center. That region hosts the largest number of businesses, particularly in Ho Chi Minh City. 2,800 businesses (37.5\%) are located in the north of Vietnam, where 
the capital, Hanoi, is a formidable economic and political power. The center of the country is less developed, and attracts fewer businesses because of unfavorable natural conditions, with only 1,226 businesses (16.4\%). Table 3 indicates the structure of the Vietnamese food industry based on two criteria: (1) number of employees; and (2) equity capital.

Table 3. Statistics on food manufacturing industries in Vietnam (2012)

\begin{tabular}{c|lc}
\hline Categories & \multicolumn{1}{c}{ Sub-categories } & Number of firms \\
\hline & Less than 100 & 5,803 \\
& 101 to 299 & 1,082 \\
Number of employees & 300 to 499 & 329 \\
& 500 to 999 & 151 \\
& Over 1,000 & 101 \\
& Total & $\mathbf{7 , 4 6 6}$ \\
\hline Equity capital & Less than 1 billion VND & 2,130 \\
(billions of VND, & 1 to 10 billion VND & 3,011 \\
1 US dollar = 22.000 VND) & 10 to 200 billion VND & 1,878 \\
& 200 to 500 billion VND & 254 \\
& Over 500 billion VND & 193 \\
\hline
\end{tabular}

Source: General Statistics Office of Vietnam, http:/www.gso.gov.vn.

To compile a list of food manufacturers in Vietnam, we contacted the food industry department of the Ministry of Industry and Trade. The Ministry provided the contact information of 700 food manufacturers for which general information was available (name of transport or logistics manager, address, telephone number). A questionnaire was mailed to the transport or logistics manager identified, given the slow development of Internet communications. One week after the mailing, we contacted the businesses by telephone to confirm that they had received our questionnaire and invited them to complete it. We received 98 responses after one month, but four were eliminated because several values were missing. To improve the response rate, manufacturers were contacted again by telephone and the respondent was invited to participate. We consequently received an additional 45 responses. In total, we received 139 usable questionnaires, for a response rate of $19.8 \%$, which is very satisfactory compared with the studies usually conducted in Europe and North America in the supply chain context. In our survey, of the 139 business respondents, 68 were located in the south (48.9\%), 42 in the north (30.2\%), and 29 in the center $(20.9 \%)$ of the country.

Company size was measured by several criteria. Our research uses the two criteria mentioned above: (1) number of employees; and (2) equity capital, along with sales turnover. Regarding the average level of number of employees of food manufacturing industries in Vietnam, the businesses in our sample are larger than average. As table 4 shows, $20.9 \%$ of businesses surveyed have fewer than 100 employees, $38.8 \%$ of businesses surveyed have between 300 and 499 employees, $10.8 \%$ of businesses surveyed have between 500 and 999 employees, and only $4.3 \%$ have over 1,000 employees. The overrepresentation of large businesses may be a source of bias in the analysis, yet we can assume that their leading-edge supply chain management practices can provide valuable information on evolution underway in Vietnam since the liberalization of the national economy. Nonetheless, Vietnam has generally not yet seen the development of sophisticated supply chains, which is also the case in other emerging countries like Bangladesh and Pakistan (Schotter and My, 2013). 
Table 4. Characteristics of manufacturers in our sample

\begin{tabular}{|c|c|c|c|}
\hline Categories & Sub-categories & Number of firms & $\%$ \\
\hline \multirow{6}{*}{ Number of employees } & Less than 100 & 29 & 20.9 \\
\hline & 101 to 299 & 35 & 25.2 \\
\hline & 300 to 499 & 54 & 38.8 \\
\hline & 500 to 999 & 15 & 10.8 \\
\hline & Over 1,000 & 6 & 4.3 \\
\hline & Total & 139 & 100 \\
\hline \multirow{6}{*}{$\begin{array}{c}\text { Equity capital } \\
\text { (billions of VND, } \\
1 \text { US dollar }=22.000 \mathrm{VND})\end{array}$} & Less than 1 billion VND & 34 & 24.5 \\
\hline & 1 to 10 billion VND & 27 & 19.4 \\
\hline & 10 to 200 billion VND & 49 & 25.3 \\
\hline & 200 to 500 billion VND & 21 & 15.1 \\
\hline & Over 500 billion VND & 8 & 5.7 \\
\hline & Total & 139 & 100 \\
\hline \multirow{6}{*}{$\begin{array}{c}\text { Sales turnover } \\
\text { (billions de VND, } \\
\text { 1 US dollar }=22.000 \text { VND) }\end{array}$} & Less than 1 billion VND & 29 & 20.9 \\
\hline & 1 to 10 billion VND & 33 & 23.7 \\
\hline & 10 to 200 billion VND & 59 & 42.4 \\
\hline & 200 to 500 billion VND & 11 & 7.9 \\
\hline & Over 500 billion VND & 7 & 5.0 \\
\hline & Total & 139 & 100 \\
\hline
\end{tabular}

Concerning equity capital, the businesses in our survey are quite present in the five categories defined by the General Statistics Office of Vietnam. Nearly one-quarter of manufacturers have equity capital of less than 1 billion VND, and the same proportion of businesses have average equity capital of between 10 billion in 200 billion VND. Only seven businesses, or 5\%, have equity capital greater than 500 billion VND. According to the sales turnover criterion, almost all of the manufacturers in the sample have a sales turnover of under 200 billion VND. $7.9 \%$ of businesses have a sales turnover of between 200 and 500 billion VND. Only 5\% of businesses report a sales turnover greater than 500 billion VND. This figure is consistent with the analysis by Gerber et al. (2014), which confirms the presence of many very small actors that are heavily involved in local commodity chains for various agri-food markets.

\section{RELIABILITY TESTS AND RESULTS}

Validating measurement instruments is a problem frequently cited in management research. For the unidimensionality and reliability tests of the measurement scales, we used SPSS software with the following criteria: Cronbach's alpha, $\mathrm{R}^{2}$, KMO, Bartlett's test and precision of sampling estimate (PSE). The first results obtained for the informational integration scale between the manufacturer and LSP indicate that the data are factorizable. The hypothesis of no correlation between the seven items is rejected by the Bartlett's test $(p<0.001)$. The KMO criterion is very satisfactory, with a value of 0.834 . This indicates a good fit of the data to the factor solution. In contrast, the PSE per statement is only 0.4 . This implies that each item is at most $40 \%$ explained by the other items. We used different methods to analyze the dimensionality of the scale. The Keiser test identifies two axes that explain $48.65 \%$ of the total variance. The scree test and the component matrix after rotation also identify two dimensions.

Principal component analysis on the seven items related to the use of monitoring data lets us identify two dimensions. The second dimension includes only item II_07. In addition, this item does not satisfy the total correlation criterion (0.067), and must be removed. After removing item II_07, we performed the second principal component analysis. Table 5 presents the final results of this principal component analysis. A new extraction without item II_07 shows higher total variance explained (56.84\%). The quality of the representation and the factor contributions of the six items are satisfactory. Because the Cronbach's alpha (0.846) indicates that the scale has good internal consistency, we retained this solution. 
Table 5. Analysis of the informational integration scale

\begin{tabular}{|c|c|c|}
\hline Items & Factor contribution & $\mathbf{R}^{2}$ \\
\hline II_01 & 0.826 & 0.682 \\
\hline II_02 & 0.777 & 0.6 \\
\hline II_03 & 0.743 & 0.55 \\
\hline II_04 & 0.735 & 0.54 \\
\hline II_05 & 0.730 & 0.50 \\
\hline II_06 & 0.708 & 0.53 \\
\hline Cronbach's alpha & \multicolumn{2}{|c|}{0.847} \\
\hline Unidimensionality & \multicolumn{2}{|c|}{ Yes } \\
\hline Variance explained & \multicolumn{2}{|c|}{$56.84 \%$} \\
\hline Factorization & \multicolumn{2}{|c|}{$\mathrm{KMO}=0.84$, Bartlett's test $p<0.001$, PSE $>0.79$} \\
\hline
\end{tabular}

Concerning the problem of identifying the dimensionality of the scale of logistics performance perceived by the manufacturer, the Kaiser criterion suggests that we should retain only one dimension, which explains $58.7 \%$ of the total variance. The scree test also graphically points to the presence of one dimension. $\mathrm{R}^{2}$ are all greater than 0.5 . The items are distributed as foreseen on one factor: factor contributions are greater than 0.716 , which indicates good measures of unidimensionality. The Cronbach's alpha (0.822) also indicates good measures of reliability. We consequently retain this solution.

The correlation matrix produces two correlations whose magnitude is greater than 0.3 , which is acceptable. The hypothesis of no correlation among the nine items is satisfactorily affirmed by the Bartlett's test $(p<0.001)$ and the KMO criterion (0.908). The PSE indicates that each item is explained more than $87 \%$ by the other items. The principal component analysis of the 11 items retained gives good results. Concretely, the eigenvalue of the first component is 7.156, whereas it is below 1 for all the other components. This is quite satisfactory in terms of the Kaiser criterion. For total variance explained, the result is also favorable. The first component explains $65.06 \%$ of the variance and appears superior to the other components. The Cronbach's alpha (0.94) indicates that the measurement scale is reliable in terms of internal consistency. Examination of the quality of the representation indicates that items have $\mathrm{R}^{2}$ greater than 0.5 . Table 6 presents the results obtained.

Table 6. Analysis of the logistics performance scale

\begin{tabular}{ccc}
\hline Items & Factor contribution & $\mathbf{R}^{\mathbf{2}}$ \\
\hline LP_01 & 0.828 & 0.686 \\
LP_02 & 0.849 & 0.721 \\
LP_03 & 0.827 & 0.683 \\
LP_04 & 0.808 & 0.653 \\
LP_05 & 0.752 & 0.565 \\
LP_06 & 0.849 & 0.561 \\
LP_07 & 0.759 & 0.575 \\
LP_08 & 0.846 & 0.716 \\
LP_09 & 0.821 & 0.675 \\
LP_10 & 0.796 & 0.634 \\
LP_11 & 0.829 & 0.687 \\
\hline Cronbach's alpha & & \\
Unidimensionality & & 0.94 \\
Variance explained & Yes & $65.05 \%$ \\
Factorization & KMO=0.908, Bartlett's test $p<0.001$, PSE $>0.87$ \\
\hline
\end{tabular}

The results obtained from the 139 respondents confirm the existence of structural relations between the dependent variables and the independent variable. The empirical investigation not only affirms the impact of the informational integration process on logistics performance perceived by the manufacturer, but also identifies factors that can improve perceived logistics performance, with a structural coefficient of 0.254 , a Student's $t$ value of 3.261 and significance of $p<0.01(\mathrm{t}>2,58)$. Therefore, the stronger the informational integration of the supply chain between the manufacturer and its LSP, the more the manufacturer perceives an improvement in its logistics performance. Our hypothesis is thus affirmed: Logistics performance is perceived by the manufacturer as improved if the manufacturer and its LSP develop an informational integration policy, with $\beta=0.254$ and $p<0.01$. Joint improvement 
of the management of interfaces through shared information systems is shown to be an important aspect of the dyadic relationship between manufacturer and LSP in the Vietnamese context.

\section{DISCUSSION AND CONCLUSION}

This paper examines a recent and promising problem that is proliferating in the literature on supply chain management. From a theoretical standpoint, the validation of our hypothesis underlines the importance of focusing on the potential impact of the use of an LSP on a shipper's performance. In managerial terms, emphasis should be placed on the effort companies should make out to successfully implement an integration policy and thus derive a solid competitive advantage.

\section{Theoretical and Managerial Contributions}

By developing a conceptual framework grounded in dyadic integration of the supply chain between Vietnamese food manufacturers and their LSPs, we have made several theoretical contributions to the logistics literature in general, and the literature on logistics performance in particular. Specifically, our literature review offers a synthesis of the research conducted on informational integration within supply chains. It clarifies the role of the LSP in logistics performance improvement. The main added value of the paper is that it examines the impact on logistics performance of the informational variable in the context of supply chain integration between a manufacturer and its LSP. The results support our hypothesis, and are consistent with the theoretical framework: the higher the informational integration, the stronger the performance (Liu et al., 2013; Maleki and Cruz-Machado, 2013; Mackelprang et al., 2014).

The specific context of this research is the food industry. This methodological choice might well explain the results. The major constraints that this sector deals with - for instance, traceability, freshness, and chilled distribution force supply chain members to coordinate very well; any dysfunction could have major negative impacts on the flow of products. This has prompted some manufacturers to integrate their information flows with that of their LSPs: such an approach facilitates information exchange and, therefore, allows for faster problem identification and the ensuing solutions. In most Western countries, the food industry is the sector recognized as having evolved the fastest in terms of logistics performance. This fast-paced evolution was a must to attain the high quality standards demanded by large retailers, themselves under pressure by final customers who were worried by food-related crises such as the "horse crisis" which happened in Europe in 2013. The high integration level between some manufacturers and their LSPs has enabled an easier flow traceability all along the supply chain; consequently, it is possible to know in real time where the products are. It appears that by using advanced information systems more often, Vietnam is progressively aligning itself with the international standards associated to supply chain monitoring.

In managerial terms, this paper proposes a set of integration mechanisms for manufacturers and their LSPs in the specific context of emerging economies. It focuses on improving logistics performance perceived by the manufacturer through integration of LSPs' logistics competencies related to the sharing of monitoring data. Based on the results obtained, two complementary viewpoints emerge:

- The manufacturer's viewpoint of supply chain integration. Manufacturers' supply chain managers must view the LSP as an essential lever of performance, yet the LSP cannot necessarily create value for its customer for all logistics services. We have thus identified logistics performance perceived by the manufacturer based on 11 items. In fact, there is no proof that an LSP has the necessary competencies to allow a manufacturer to achieve the strongest logistics performance on each item (or performance criterion). In other words, when a firm decides to use an LSP, supply chain managers at the manufacturer must clearly define their expectations in terms of cost, service, responsiveness, modularity, etc., and confirm the fit between the offer of each LSP and their expectations.

- LSP's viewpoint of supply chain integration. Top management of LSPs need to exhibit a will to achieve informational integration only with clearly interested customers. This means they must consider the appropriate use of information resources as an important condition to obtain and maintain a sustainable competitive advantage. These resources allow an LSP to support rich interaction with its customers as part of outsourcing contracts. Informational integration can also guarantee better tracking 
and tracing of products, and thus facilitate the integration of manufacturers in global supply chains that increasingly require compliance with high quality standards.

\section{Limitations and Perspectives}

Like all research, our study has limitations. The first limitation of our work is methodological. We used a quantitative approach to discuss the validity of our hypothesis. In fact, an exploratory study that rests on a qualitative approach is often an indispensable prerequisite for all quantitative studies because it lets researchers define and familiarize themselves with the research question. However, due to time constraints and limited resources, we could not follow this method. In particular, we could not conduct face-to-face interviews with supply chain managers of the food manufacturing industry and logistics industry in Vietnam. Doing so would have let us refine our approach to outsourcing logistics, and analyze how well it corresponds to the case of outsourcing strategies in other countries.

The second methodological limitation pertains to the evaluation of logistics performance, which can be measured by several criteria. This question has been largely debated in the literature (Beamon, 1999). We have retained 11 criteria to understand this performance, and they may not necessarily be considered as the most relevant for businesses in all cases. Although this choice is justified by the research conduct conditions (improved response rate, reduced survey cost, etc.), we are aware of the limits it imposes. The view that we obtain of logistics performance in Vietnam is thus restricted to this country, especially because we have evaluated perceptions and not the reality of logistics performance. Although analysis based on perceptions is widespread in logistics studies (Daugherty et al., 1996), it does not account for performance actually obtained from objective measures (lower logistics costs, higher service rate, etc.).

These two limits suggest future research avenues. Undeniably, cultural specificity plays an important role in understanding supply chain governance mechanisms and, more broadly, implementation of business-to-business cooperative strategies (Cannon et al., 2010). Vietnam is marked by a long and tumultuous history that has certainly forged social and cultural frameworks that presumably influence business relations; powerful personal networks and corrupt practices are also quite salient and increase the perceived risk in outsourcing relationships (Lam, 2011). One of the major questions is therefore the extent that mutual knowledge among decision-makers, at both the manufacturer and the LSP, impacts the informational integration process: what about proprietary information which (potential) competitors may have to share with LSPs? Are there safeguards on this, and does it affect willingness to pool information? It would surely be worth expanding the investigation to contexts other than Vietnam, where trust, commitment and information sharing rest on different bases.

Similarly, by preserving the cultural unity specific to Vietnam, we could also envision additional research in this country from LSPs' standpoint. Perceived logistics performance indeed results from continuous interaction between two partners that agree to initiate business-to-business decompartmentalization to jointly construct a more effective and efficient exchange system. We therefore call for research into the cross-functional impact of informational integration of the supply chain, on the seller and buyer of logistics services simultaneously. To fully grasp the subtlety of the decision mechanisms involving a manufacturer and its LSP, conducting in-depth case studies would be useful. Quantitative approaches have their advantages, particularly for validation of measurement scales and hypothesis testing, but they do not allow one to capture the complexity of contractual and non-contractual arrangements made within supply chains. The daily practice of logistics monitoring undeniably rests on tacit knowledge and mutual adjustments, whose richness and extreme complexity cannot be easily captured by a closedended questionnaire.

\section{ACKNOWLEDGEMENTS}

The authors would like to express their thanks to Christine Belin-Munier, Valentina Carbone, Jean Nollet, Aurélien Rouquet and Mary Teagarden who provided valuable input to substantially improve the first draft of this paper. 


\section{AUTHOR BIOGRAPHIES}

Huu Tuyen Duong is Associate Professor of Supply Chain Management at the University of Transport \& Communications, Hanoi (Vietnam). He holds a PhD in Management from Aix-Marseille University, and he has published numerous papers on supply chain management, logistical services and food manufacturing in Vietnam. Some of his papers have appeared in journals as Cahiers Scientifiques du Transport and Innovations, and his work has been presented at international conferences. He is currently working on a book on logistics outsourcing strategies in Vietnam. Email: duonghuutuyendhgtvt@yahoo.fr.

Gilles Paché is Professor of Retailing and Supply Chain Management at the Aix-Marseille University, Aix-enProvence (France). He has more than 350 publications in the forms of journal papers, books, edited books, edited proceedings, edited special issues, book chapters, conference papers, and reports. He is Deputy Director of the Centre de Recherche sur le Transport et la Logistique (CRET-LOG), and his major interests are network organizations, supply chain management, and retail operations management. Email: gilles.pache@univ-amu.fr.

\section{REFERENCES}

Alfalla-Luque, R., Medina-Lopez, C., \& Dey, P. (2012). Supply chain integration framework using literature review. Production Planning \& Control, 24(8-9), 800-817.

Auramo, J., Kauremaa, J., \& Tanskanen, K. (2005). Benefits of IT in supply chain management: an explorative study of progressive companies. International Journal of Physical Distribution \& Logistics Management, 35(2), 82-100.

Banomyong, R., Thai, V., \& Yuen, K. (2015). Assessing the national logistics system of Vietnam. Asian Journal of Shipping \& Logistics, 31(1), 21-58.

Beamon, B. (1999). Measuring supply chain performance. International Journal of Operations \& Production Management, 19(3), 275-292.

Berry, D., \& Naim, M. (1996). Quantifying the relative improvements of redesign strategies in a PC supply chain. International Journal of Production Economics, 46-47, 181-196.

Bowersox, D., Closs, D., Stank, P., \& Keller, S. (2000). How supply chain competency leads to business success. Supply Chain Management Review, 4(4), 70-78.

Cannon, J., Doney, P., Mullen, M., \& Peterson, K. (2010). Building long-term orientation in buyer-supplier relationships: the moderating role of culture. Journal of Operations Management, 28(6), 506-521.

Carr, A., Kaynak, H., \& Muthusamy, S. (2008). The cross-functional coordination between operations, marketing, purchasing and engineering and the impact on performance. International Journal of Manufacturing Technology \& Management, 13(1), 55-77.

Chow, G., Heaver, T., \& Henriksson, L. (1994). Logistics performance: definition and measurement. International Journal of Physical Distribution \& Logistics Management, 24(1), 17-28.

Closs, D., \& Bowersox, D. (1997). Logistical management: the integrated supply chain process. New York (NY): McGraw-Hill.

Closs, D., \& Savitskie, K. (2003). Internal and external logistics information technology integration. International Journal of Logistics Management, 14(1), 63-76.

Dao, D. (2011). Logistics in Vietnam: the main issues. Hanoi: National University of Economics Press [in Vietnamese].

Daugherty, P., Stank, T., \& Rogers, D. (1996). Third-party logistics service providers: purchasers' perceptions. Journal of Supply Chain Management, 32(2), 23-29.

Devaraj, S., Wei, S., \& Krajewski, L. (2007). Impact of e-business technologies on operational performance: the role of production information integration in the supply chain. Journal of Operations Management, 25(6), 1199-1216.

Dröge, C., Jayaram, J., \& Vickery, S. (2004). The effects of internal versus external integration practices on time-based performance and overall firm performance. Journal of Operations Management, 22(6), 557-573.

Fabbe-Costes, N., Jahre, M., \& Roussat, C. (2008). Supply chain integration: the role of logistics service providers. International Journal of Productivity \& Performance Management, 58(1), 71-91.

Forslund, H. (2012). Performance management in supply chains: logistics service providers' perspective. International Journal of Physical Distribution \& Logistics Management, 42(3), 296-311.

Frohlich, M., \& Westbrook, R. (2002). Demand chain management in manufacturing and services: web-based integration, drivers and performance. Journal of Operations Management, 20(6), 729-745.

Gerber, J., Turner, S., \& Milgram, B. (2014). Food provisioning and wholesale agricultural commodity chains in Northern Vietnam. Human Organization, 73(1), 50-61.

Gimenez, C., \& Ventura, E. (2005). Logistics-production, logistics-marketing and external integration: their impact on performance. International Journal of Operations \& Production Management, 25(1), 20-38.

Graham, G., \& Hardaker, G. (2000). Supply chain management across the Internet. International Journal of Physical Distribution \& Logistics Management, 30(3-4), 286-295. 
Green, K., Jr., Whitten, D., \& Inman, R. (2008). The impact of logistics performance on organizational performance in a supply chain context. Supply Chain Management: An International Journal, 13(4), 317-327.

Gunasekaran, A., \& Ngai, E. (2003). The successful management of a small logistics company. International Journal of Physical Distribution \& Logistics Management, 33(9), 825-842.

Halldórsson, A., \& Skjøtt-Larsen, T. (2004). Developing logistics competencies through third party logistics relationships. International Journal of Operations \& Production Management, 24(2), 192-206.

Hertz, S., \& Alfredsson, M. (2003). Strategic development of third party logistics providers. Industrial Marketing Management, 32(2), 139-149.

Holmberg, S. (2000). A systems perspective on supply chain measurements. International Journal of Physical Distribution \& Logistics Management, 30(10), 847-868.

Hsiao, H., Kemp, R., \& Van der Vorst, J. (2010). A classification of logistic outsourcing levels and their impact on service performance: evidence from the food processing industry. International Journal of Production Economics, 124(1), 7586.

Hsu, C.-C., Kannan, V., Tan, K.-C., \& Leong, G.-K. (2008). Information sharing, buyer-supplier relationships, and firm performance: a multi-region analysis. International Journal of Physical Distribution \& Logistics Management, 38(4), 296-310.

Iyer, K., Germain, R., \& Frankwick, G. (2004). Supply chain B2B e-commerce and time-based delivery performance. International Journal of Physical Distribution \& Logistics Management, 34(8), 645-661.

Jayaram, J., \& Tan, K.-C. (2010). Supply chain integration with third-party logistics providers. International Journal of Production Economics, 125(2), 262-271.

Kärkkäinen, M., Laukkanen, S., Sarpola, S., \& Kemppainen, K. (2007). Roles of interfirm information systems in supply chain management. International Journal of Physical Distribution \& Logistics Management, 37(4), 264-286.

Kim, S. (2006). The effect of supply chain integration on the alignment between corporate competitive capability and supply chain operational capability. International Journal of Operations \& Production Management, 26(10), 1084-1107.

Kim, D. (2013). Relationship between supply chain integration and performance. Journal of Operations Management Research, 6(1), 74-90.

Kim, D., \& Lee, R. (2010). Systems collaboration and strategic collaboration: their impacts on supply chain responsiveness and market performance. Decision Sciences, 41(4), 955-981.

Kulp, S., Lee, H., Ofek, E. (2004). Manufacturer benefits from information integration with retail customers. Management Science, 50(4), 431-444.

Lam, T. (2011). Vietnam outsourcing risks management. Journal of Applied Business Research, 27(1), 51-59.

Lee, H. (2000). Creating value through supply chain integration. Supply Chain Management Review, 4(4), 30-36.

Leuschner, R., Rogers, D., \& Charvet, F. (2013). A meta-analysis of supply chain integration and firm performance. Journal of Supply Chain Management, 49(2), 34-57.

Li, L., \& Zhang, H. (2008). Confidentiality and information sharing in supply chain coordination. Management Science, 54(8), $1467-1481$.

Lin, F.-R., Huang, S.-H., \& Lin, S.-C. (2002). Effects of information sharing on supply chain performance in electronic commerce. IEEE Transactions on Engineering Management, 49(3), 258-268.

Liu, H., Ke, W., Wei, K.-K., \& Hua, Z. (2013). Effects of supply chain integration and market orientation on firm performance: evidence from China. International Journal of Operations \& Production Management, 33(3), 322-346.

Liu, X., Grant, D., McKinnon, A., \& Feng, Y. (2010). An empirical examination of the contribution of capabilities to the competitiveness of logistics service providers: a perspective from China. International Journal of Physical Distribution \& Logistics Management, 40(10), 847-866.

Lummus, R., \& Vokurka, R. (1999). Managing the demand chain through managing the information flow: capturing moments of information. Production \& Inventory Management Journal, 40(1), 16-20.

Mackelprang, A., Robinson, J., Bernardes, E., \& Webb, G. (2014). The relationship between strategic supply chain integration and performance: a meta-analytic evaluation and implications for supply chain management research. Journal of Business Logistics, 35(1), 71-96.

Maleki, M., \& Cruz-Machado, V. (2013). An empirical review on supply chain integration. Management \& Production Engineering Review, 4(1), 85-96.

Maloni, M., \& Carter, C. (2006). Opportunities for research in third-party logistics. Transportation Journal, 45(2), 23-38.

Meyer, K., Tran, Y., \& Nguyen, H. (2006). Doing business in... Vietnam. Thunderbird International Business Review, 48(2), 263-290.

Mortensen, O., \& Lemoine, O. (2008). Integration between manufacturers and third party logistics providers? International Journal of Operations \& Production Management, 28(4), 331-359.

Narasimhan, R., \& Kim, S. (2002). Effect of supply chain integration on the relationship between diversification and performance: evidence from Japanese and Korean firms. Journal of Operations Management, 20(3), 303-323.

Narasimhan, R., \& Nair, A. (2005). The antecedent role of quality, information sharing and supply chain proximity on strategic alliance formation and performance. International Journal of Production Economics, 96(3), 301-313. 
Neely, A., Gregory, M., \& Platts, K. (1995). Performance measurement system design: a literature review and research agenda. International Journal of Operations \& Production Management, 15(4), 80-116.

Paixão, A., \& Marlow, P. (2003). Fourth generation ports-A question of agility? International Journal of Physical Distribution \& Logistics Management, 33(4), 355-376.

Panayides, P., \& Song, D.-W. (2008). Evaluating the integration of seaport container terminals in supply chains. International Journal of Physical Distribution \& Logistics Management, 38(7), 562-584.

Prajogo, D., \& Olhager, J. (2012). Supply chain integration and performance: the effects of long-term relationships, information technology and sharing, and logistics integration. International Journal of Production Economics, 135(1), 514-522.

Qrunfleh, S., \& Tarafdar, M. (2014). Supply chain information systems strategy: impacts on supply chain performance and firm performance. International Journal of Production Economics, 147(B), 340-350.

Rodrigues, A., Stank, T., \& Lynch, D. (2004). Linking strategy, structure, process, and performance in integrated logistics. Journal of Business Logistics, 25(2), 65-94.

Saeed, Malhotra, M., Grover, V. (2005). Examining the impact of inter-organizational systems on process efficiency and sourcing leverage in buyer-supplier dyads. Decision Sciences, 36(3), 365-396.

Sahin, F., \& Robinson, E., Jr. (2005). Information sharing and coordination in make-to-order supply chains. Journal of Operations Management, 23(6), 579-598.

Sanders, N., \& Premus, R. (2005). Modeling the relationship between firm IT capability, collaboration, and performance. Journal of Business Logistics, 26(1), 1-23.

Savitskie, K. (2007). Internal and external logistics information technologies: the performance impact in an international setting. International Journal of Physical Distribution \& Logistics Management, 37(6), 454-468.

Schotter, A., \& My, H. (2013). The effects of the global financial crisis on supply chain members in non-BRIC emerging markets. Thunderbird International Business Review, 55(5), 609-618.

Sezen, B. (2008). Relative effects of design, integration and information sharing on supply chain performance. Supply Chain Management: An International Journal, 13(3), 233-240.

Shore, B., \& Venkatachalam, A. (2003). Evaluating the information sharing capabilities of supply chain partners: a fuzzy logic model. International Journal of Physical Distribution \& Logistics Management, 33(9), 804-824.

Skjoett-Larsen, T., Halldorsson, A., Andresson, A., Dreyer, D., Virum, H., \& Ojala, L. (2006). Third party logistics-A Nordic research approach. International Journal of Value Chain Management, 1(2), 190-204.

Stank, T., Keller, S., \& Daugherty, P. (2001). Performance benefits of supply chain logistical integration. Transportation Journal, 41(2-3), 32-46.

Strader, F., \& Shaw, M. (1999). The impact of information sharing on order fulfillment in divergent differentiation supply chain. Journal of Global Information Management, 7(1), 17-25.

Swink, M., Narasimhan, R., \& Viswanatham, S. (2007). Managing beyond the factory walls: effects of four types of strategic integration on manufacturing plant performance. Journal of Operations Management, 25(1), 148-164.

Vo, T.-Q., Swierczek, F., \& Nguyen, D.-K. (2013). Corporate performance of privatized firms in Vietnam. Journal of Applied Business Research, 29(5), 1437-1450.

White, A., Daniel, E., \& Mohdzain, M. (2005). The role of emergent information technologies and systems in enabling supply chain agility. International Journal of Information Management, 25(5), 396-410.

Wilding, R., \& Juriado, R. (2004). Customer perceptions on logistics outsourcing in the European consumer goods industry. International Journal of Physical Distribution \& Logistics Management, 34(8), 628-644.

Wu, F., Yeniyurt, S., Kim, D., \& Cavusgil, S. (2006). The impact of information technology on supply chain capabilities and firm performance: a resource-based view. Industrial Marketing Management, 35(4), 493-504.

Yu, Z., Yan, H., \& Cheng, T. (2001). Benefits of information sharing with supply chain partnerships. Industrial Management \& Data Systems, 101(3), 114-121.

Zailani, S., \& Rajagopal, P. (2005). Supply chain integration and performance: US versus East Asian companies. Supply Chain Management: An International Journal, 10(5), 379-393.

Zhao, X., Xie, J., \& Zhang, W. (2002). The impact of information sharing and order-coordination on supply chain performance. Supply Chain Management: An International Journal, 7(1), 24-40. 